\title{
PHỤC HÌNH THẨM MỸ RĂNG TRƯớC SỬ DỤNG KỸ THUÂTT MặT DÁN SỨ E.MAX
}

\section{TÓM TẮT}

Nghiên cứu được thực hiên trên 31 bệnh nhân có chỉ định phục hình thẩm mỹ răng trước sử dụng kỹ thuật mặt dán sứ E.max đến khám và điều trị tại 1 số cơ sởRăng hàm măt trên đia bàn Hà Nội trong khoảng thời gian từ tháng 7/2020 đến tháng 4/2021 nhằm đánh giá kết quả phục hình thẩm mỹ răng trước sử dụng kỹ thuật mặt dán sứ E.max. Đối tượng và phương pháp nghiền cứu: Là nghiên cứu mô tả kết quả lâm sàng không đối chứng, theo mô hình trước sau. Viêc nghiên cứu được thức hiện trên 31 bênh nhân với 96 đơn vị mặt dán sứ E.max, và kết quả, kết luân là: Sau khi phuc hình măt dán sứ E.max được thực hiện thu được tỷ lệ đánh giá mức độ tốt về hình thể là 93 đơn vị phục hình $(96,88 \%)$, màu sắc là 96 đơn vị (100\%), đường viền lợi là 94 đơn vị (97,92\%). Sau 3 tháng: hình thể, màu sắc không thay đồi, đường viền lợi tăng lên với mức độ mức độ tốt 100\%. Độ bền, phát âm bình thường, chức năng nhai, sự hài lòng bềnh nhân là đat $100 \%$

Tư khóa: Mặt dán sứ E.max, thẩm mỹ răng trước

\section{SUMMARY \\ AESTHETIC RESTORATION FOR INCISORS, CANINES AND PREMOLARS USING E.MAX VENEER TECHNIQUE}

The research was performed with 31 patients with aesthetic restoration for incisors, canines, and premolars using E.max veneer technique. These patients have checkup and treatment at some dental facilities in Hanoi from July 2020 to April 2021. The research is to assess results of aesthetic restoration for incisors, canines, and premolars using E.maxveneer technique. Research subject and method: the research of non-controlled clinical outcomes according to the pre and post model. The research was carried out on 31 patients with 96 E.max veneers. It is concluded that after E.max veneer restoration has been performed, the good assessment rate of appearance, color, and gingivalmargin are 93 restoration units $(96.88 \%), 96$ units $(100 \%), 94$ units $(97.92 \%)$ respectively. After three months, appearance and color are unchanged, gingivalmargin reaches $100 \%$ of goodness, viscosity and pronunciation are normal, and chewing function and patient satisfaction reach $100 \%$.

Key words: E.max veneer, aesthetic restoration for incisors, canines, and premolars

*Bệnh viện YHCT, Bộ Công An

**Bênh viên RHM Trung ương Hà Nôi

Chịu trách nhiệm chính: Mai Văn Đức

Email: duchien39@gmail.com

Ngày nhâan bài: 14/3/2021

Ngày phản biên khoa hoc: 10/4/2021

Ngày duyệt bài: $5 / 5 / 2021$

\section{Mai Văn Đức*, Chu Thị Quỳnh Hương** I. ĐĂT VẤN ĐỀ}

Ngày nay, với đời sống ngày càng cao, nhu cầu chăm sóc sức khỏe răng miệng ngày càng tăng lên và đặc biệt là nhu cầu về phục hình thẩm mỹ răng trước. Đối với những bệnh nhân có răng bị xấu về màu sắc, bất thường về hình thể, mất tổ chức cứng, lệch lạc mức độ nhẹ,bất cân xứng chiều cao các răng cửa cùng tên thì trước đây thường được chỉ định chụp sứ. Tuy nhiên việc điều trị bằng chụp sứ phải mài nhiều mô răng, thay đổi cảm giác ăn nhai, dễ kích thích mô nha chu. Vì vậy kỹ thuật mặt dán sứ được thay thế với nhiều ưu điểm vượt trội là: mài răng ít, bảo tồn mô răng, đường viền cồ răng nguyên vẹn, tính thẩm mỹ cao, tương hợp tốt với mô mềm, bền vững trong thời gian dài, có những trường hợp không phải mài răng 1,2,3,4,5

Hiện nay, cùng với sự phát triển của khoa hoc công nghệ, vật liệu sứ nha khoa ra đời với nhiểu tên gọi khác nhau và ngày càng được cải tiến, sử dụng rộng rãi hơn. Đáng chú ý là sự ra đời của vật liệu sứ không kim loại Emax (hã̉ng IVOCLAVIVADENT). Thường được chỉ định trong phục hình các răng trước. So với vật liệu toàn sứ zirconia: khung zirconcó sự dẫn truyền ánh sáng kém hơn (khi sử dụng cho răng trước thường bị đục), không sử dụng etching và dán dính được ${ }^{6}$, trong khi đó thì sứ Emax khắc phục được nhược điểm này? ${ }^{7}$. Do đó sứ Emax được sử dụng trong kỹ thuật mă̆t dán sứ răng trước

Ở Việt Nam, hiện vật liệu sứ Emax đã được đưa vào sử dụng trong lâm sàng nhưng chưa có nhiều nghiên cứu, đặc biệt kỹ thuật sử dụng mặt dán sứ trong phục hình thẩm mỹ răng trước đã được tiến hành khá phổ biến trên lâm sàng nhưng có rất ít nghiên cứu đánh giá kết quả về kỹ thuật này. Vì vậy chúng tôi chọn đề tài nghiên cứu: "Kêt quả phục hinh thẩm mỹ răng trước sử dụng kỹ thuật mặt dán sứ Emax tại một số cơ sở Răng Hàm Mặt"với 2 mục tiêu:

- Mô tả đặc điêm lâm sàng, cận lâm sàng của các bệnh nhân được chỉ định phục hình thẩm mỹ răng trước sử dụng kỹ thuật mặt dán sứ Emax tại môt số cơ sở Răng Hàm Mặt trên

- Nhận xét kết quả phục hinh thẩm mỹ răng trước sử dụng kỹ thuật mặt dán sứ Emax cho nhóm bệnh nhân trên

II. ĐỐI TƯợNG VÀ PHƯƠNG PHÁP NGHIÊN CỨU 


\section{1. Đối tượng}

- Tiêu chuẩn lựa chọn: Tất cả những bệnh nhân có chỉ định phục hình thẩm mỹ răng trước sử dụng kỹ thuật mặt dán sứ, đến khám và điều trị tại khoa phục hình bệnh viện răng hàm mặt trung ương Hà Nội, trung tâm nha khoa 225 Trường Chinh -Viện Đào Tạo Răng Hàm Mặt từ tháng 7/2020 đến tháng 4/2021.

- Tiêu chuẩn loại trừ: Bênh nhân có thói quen xấu tạo nên các lực quá lớn trên phục hình, bệnh nhân có vấn đề về tâm lí không hợp tác với bác sĩ, bệnh nhân không có điều kiện để kiểm tra theo dõi đánh giá theo lịch hen. Các răng trước có chống chỉ định sử dụng kỹ thuật mặt dán sứ.

\section{Phương pháp}

- Là một phương pháp nghiên cứu mô tả kết quả lâm sàng không đối chứng, theo mô hình "trước-sau"

- Thời gian nghiên cứu: từ tháng 7/2020 đến tháng 4/2021. Trong nghiên cứu của chúng tôi số lượng răng nghiên cứu là 96 răng

- Phương pháp tiến hành:

+ Nguyên tắc: bảo tồn men răng tối đa (có trường hợp không phải mài răng), có bộ mũi khoan kim cương để mài sửa soạn chuyên biệt, lựa chọn kiểu mặt dán sứ, mài mặt bên và mài rìa cắn, tạo được sự ổn định ban đầu, phục hồi thân răng trước khi làm mặt dán sứ, phục hình tạm thẩm mỹ khi chờ gắn mặt dán sứ

+ Các bước tiến hành: lấy dẫu, đổ mẫu nghiên cứu và ghi tương quan hai hàm bằng sáp ở khớp cắn trung tâm, lên kế hoạch điêu trị, làm Wax- up sáp, làm Mock-uptrên miệng bệnh nhân,mài sửa soạn cho phục hình mặt dán sứ, đặt chi co nướu, so màu rằng và gửi labo, làm răng tam, gắn phục hình

*Wax-up sáp: làm Wax up sáp trên mẫu đã được điêu chỉnh, Wax-up sáp sẽ định hình trước hình dạng và đô dày của mặt dán sứ sau này. Lây dấu khóa mẫu đã được làm Wax up bằng silicon (lây 2 mẫu: mẫu 1 để làm mock-up và răng tạm, mẫu 2 dùng để làm dấu khóa silicon để kiểm tra mức độ mài răng khi mài cùi)

*Sử dụng dấu silicon đầu tiên cho nhựa làm răng tạm và đặt vào cung răng bệnh nhân,khi vật liệu nhựa tạm đã trùng hợp hết thì lấy dấu silicon ra cẩn thẩn, loại bỏ nhựa thừa bằng dụng cụ thích hợp, giữ lại dấu silicon để sau khi mài cùi làm răng tạm, lúc này ở trên miệng chính là mô phỏng mặt dán sứ chính thức sau này

*Trong trường hợp mặt dán sứ bắt buộc phải sữa soạn răng thì sẽ tiển hành sửa soạn nhu sau: đặt chỉ co nưỡu để bảo vệ lợi, đặt matrix để trách tổn thương răng kế cận,xác định độ sâu cần mài bằng mũi mài đánh dấu, mài mă̆t ngoài 0.3-0.7 mm men răng bằng mũi khoan đánh dấu với 2 bình diện giải phẫu răng, dùng mũi khoan kim cương trụ thuôn để mài hoàn tất, dùng dấu khóa làm từ mẫu silicon thứ 2 để kiểm tra độ dày đã mài, mài đường hoàn tất bờ cong, trên, ngang hoặc dưới lợi, làm tròn các góc. Mài mặt bên theo nguyên tắcbảo toàn điểm tiếp giáp khi không có khe thưa và ngược lại, đường hoàn tất bờ cong. Mài rìa cắn: loại cửa sổ và Feathe không mài hạ thấp rìa cắn, loại Butt margin mài rìa căn $0,5-1 \mathrm{~mm}$, loại phủ một phần mặt trong thì mài rìa cắn $2 \mathrm{~mm}$ và một phần mặt trong

*Gắn phục hình: Thử phục hình, chuẩn bị bề mặt trong của mặt dán sứ, chuấn bị bề mặt răng. Cách ly các răng bên cạnh bằng teflon,cho Ciment Variolink vào mặt dán đặt lên mặt răng, lấy hết chất gắn thừa bằng chỉ tơ nha khoa, chiếu đèn quang trùng hợp

*Mặt dán sứ E.max sau khi được gắn sẽ được kiểm tra và hoàn thiện

3. Xử lý số liệu: Sử dụng phần mềm thống kê y học SPSS 20.0 với các thuật toán mô tả tỷ lệ với mức ý nghĩa thống kê $p<0,05$

4. Đạo đức nghiên cứu: Nghiên cứu tuân thủ đầy đủ các nguyên tắc đạo đức của nghiên cứu y học. Bệnh nhân tự nguyện tham gia nghiên cứu, các thông tin liên quan bệnh nhân được bảo mật

\section{KẾT QUẢ NGHIÊN CỨU}

Kết quả ngay sau khi phục hình răng trước bằng mặt dán sứ E.max được đánh giá về mặt thẩm mỹ với 3 tiêu chí, đó là hình thể, màu sắc, và đường viền lợi của răng phục hình được trình bày ở bảng 1 . Về hình thể với tổng số 96 đơn vị phục hình thì 93đơn vị đạt mức độ tốt (chiếm 96,88\%), màu sắc đẹp đạt $100 \%$, đường viền lợi đạt mức độ tốt 94 đơn vị phục hình (chiếm 97,92\%).

Bảng 1. Đánh giá kết quả phục hồi thẩm mỹ theo vi trí nhóm răng sau phục hình

\begin{tabular}{|c|c|c|c|c|c|c|c|c|c|c|}
\hline \multirow{3}{*}{ Tiêu chuẩn đánh } & \multicolumn{4}{|c|}{ Răng cửa \& Răng nanh } & \multicolumn{4}{|c|}{ RHN } & \multicolumn{2}{|c|}{ Tống số } \\
\hline & & & & & & ốt & & & & \\
\hline & SL & $\%$ & SL & $\%$ & SL & $\%$ & SL & $\%$ & SL & $\%$ \\
\hline Hình thế & 86 & 89,59 & 2 & 2,08 & 7 & 7,29 & 1 & 1,04 & 96 & 100 \\
\hline Màu sắc & 88 & 91,67 & 0 & 0 & 8 & 8,33 & 0 & 0 & 96 & 100 \\
\hline Đường viền lợi & 86 & 89,59 & 2 & 1,04 & 8 & 8,33 & 0 & 0 & 96 & 100 \\
\hline
\end{tabular}


Theo dõi sau 3 tháng phục hình được trình bày ở bảng 2, gồm các tiêu chí:

- Tỷ lệ đẹp về hình thể là không thay đổi

- Tỷ lệ đẹp về màu sắc là không thay đổi

- Tỷ lệ đường viện lợi mức độ tốt tăng lên và đạt $100 \%$

Bảng 2. Đánh giá kêt quả phục hồi thẩm mỹ theo vị trí nhóm răng sau 3 tháng

\begin{tabular}{|c|c|c|c|c|c|c|c|c|c|c|c|c|c|c|}
\hline \multirow{3}{*}{$\begin{array}{l}\text { Tiêu chuẩn } \\
\text { đánh giá }\end{array}$} & \multicolumn{6}{|c|}{ Răng cửa\& Răng nanh } & \multicolumn{6}{|c|}{ RHN } & \multicolumn{2}{|c|}{ Tống số } \\
\hline & \multicolumn{2}{|c|}{ Tốt } & \multicolumn{2}{|c|}{ TB } & \multicolumn{2}{|c|}{ Kém } & \multicolumn{2}{|c|}{ Tốt } & \multicolumn{2}{|c|}{ TB } & \multicolumn{2}{|c|}{ Kém } & & \\
\hline & SL & $\%$ & SL & $\%$ & SL & $\%$ & SL & $\%$ & SL & $\%$ & SL & $\%$ & SL & $\%$ \\
\hline Hình thế & 86 & 89,59 & 2 & 2,08 & 0 & 0 & 7 & 7,29 & 1 & 1,04 & 0 & 0 & 96 & 100 \\
\hline Màu sắc & 88 & 91,67 & 0 & 0 & 0 & 0 & 8 & 8,33 & 0 & 0 & 0 & 0 & 96 & 100 \\
\hline Đường viền lơi & 88 & 91,67 & 0 & 0 & 0 & 0 & 8 & 8,33 & 0 & 0 & 0 & 0 & 96 & 100 \\
\hline
\end{tabular}

Kết quả sau 3 tháng phuc hình:

- Tất cả 96 đơn vị phục hình đều có tổ chức quanh răng tốt, không sẩu răng, không ê buốt, không bị nhạy cảm bởi các kích thích, chụp X. quang hoàn toàn bình thường

- Tất cả 31 bệnh nhân nghiên cứu đều có tổ chức quanh răng bình thường

- Tất cả các đơn vị phục hình sau 3 tháng không có hiện tượng sứt mẻ sứ, võ sườn, bong mặt dán. Kểt quả cũng cho thấy không có sự khác biệt về đô bền của phưc hình mă̆t dán sứ Emax đối với vùng răng cửa, răng nanh, răng hàm nhỏ

Theo dõi sau 3 tháng phục hình được trình bày ở bảng 3 , gồm các tiêu chí chức năng nhai và sự hài lòng của bệnh nhân:

- Tất cả các răng phục hình đều có chức năng nhai bình thường

- Tất cả các răng phục hình bệnh nhân đều hài lòng

Bảng 3. Đánh giá kêt quả phục hồi chức năng nhai và sự hài lòng của bệnh

\begin{tabular}{|c|c|c|c|c|c|c|c|c|}
\hline \multirow{2}{*}{ Tiêu chí đánh giá } & \multicolumn{2}{|c|}{ Tốt } & \multicolumn{2}{c|}{ Trung bình } & \multicolumn{3}{c|}{ Kém } & \multicolumn{2}{c|}{ Tống Số } \\
\cline { 2 - 9 } & SL & \% & SL & $\mathbf{\%}$ & SL & $\mathbf{\%}$ & SL & $\mathbf{\%}$ \\
\hline Chức năng nhai & 96 & 100 & 0 & 0 & 0 & 0 & $\mathbf{9 6}$ & $\mathbf{1 0 0}$ \\
\hline Sự hài lòng của bệnh nhân & 96 & 100 & 0 & 0 & 0 & 0 & $\mathbf{9 6}$ & $\mathbf{1 0 0}$ \\
\hline
\end{tabular}

\section{BÀN LUÂ̂N}

Kết quả sau phục hình được đánh giá tại hai giai đoạn, ngay sau khi phục hình được thực hiện và sau phục hình 3 tháng

Ngay sau khi phục hình:

- Hình thể phục hình: Hình thể bên ngoài của mặt dán sứ E.max được đánh giá là rất tốt, với tổng số 96 đơn vị phục hình thì chỉ có 3 đớn vị phục hình (chỉ chiếm 3,12\%) được đánh giá hình thể ở mức trung bình, số còn lại đều có hình thể tốt.

- Đánh giá về mức độ tốt của đường viền lợi cho các đơn vị phục hình thì chỉ có 2 đơn vị có đường viền lợi ở mức trung bình, số còn lại đều tốt

- Màu sắc được đánh giá đẹp giống như màu sắc răng tự nhiên là 96 đơn vị phục hình (chiếm $100 \%)$. Màu sắc của phục hình tự nhiên giống răng thật, hài hoà với các răng trển cung hàm, phục hình có tính dẫn truyền ánh sáng như răng tự nhiên, có độ trong mờ, có hiệu ứng phát huỳnh quang. Trên tổng thể hàm răng được phục thẩm mỹ răng trước bằng mặt dán sứ E.max có được sự hài hoà, sống động tự nhiên khi nhìn vào.

\section{Sau phục hình 3 tháng:}

- Những yễu tố sau 3 tháng phục hình không thay đổi là: Phát âm, khớp cắn, thẩm mỹ chung, hình thể phục hình. Đây cũng là những yếu tố ít thay đổi theo thời gian

- Việc đánh giá độ bền của một phục hình phải thực hiện sau một thời gian dài theo dõi, tuy nhiển do thời gian thực hiện đề tài có hạn, chúng tôi chỉ đánh giá được sau 3 tháng điều trị. Đây là một trong những hạn chế của nghiên cứu này. Trong nghiên cứu này với tổng số 96 đơn vị phục hình thực hiên cho 31 bệnh nhân, chúng tôi không phát hiện bất kỳ trường hợp nào bị rạn, nứt, võ sứ. Do đó độ bền của phục hình là $100 \%$ ở cả hai nhóm răng cửa, răng nanh và răng hàm hàm nhỏ.

Tuy nhiên theo nghiên cứu của Peumans $M$, Van Meerbeek B, Lambrechts $P$, Vuylsteke Wauters M, Vanherle $G$ năm 1998 về 87 veneer sứ được đặt ở răng trước trên 25 bệnh nhân trong 5 năm thì có $93 \%$ veneers đạt yêu cầu mà không cần can thiệp ${ }^{8}$

- Tình trạng răng trụ: Đối với răng phục hình có tủy sống không có trường hợp nào bị kích thích tủy, không có viêm tủy. Không có răng trụ nào bị lung lay, trên hình ảnh $X Q$ so với ngay sau khi lắp phục hình xương ổ răng không bị tiêu, không có hiện tượng sâu răng thứ phát ở bờ phục hình hoặc cổ răng.

- Đường hoàn tất phục hình, tiếp xúc phục hình với răng bên cạnh không thay đổi sau 3 tháng 
- Đường viền lợi của răng phục hình là rất tốt sau 3 tháng đạt $100 \%$ mức độ đẹp về hình thể và màu sắc (tăng thêm 2 đơn vị phục hình từ trung bình lên tốt). Đó là do sau 3 tháng phục hình bệnh nhân đã biết cách vệ sinh răng miệng và thích nghi với sự hiện diện của phục hình

- Sau phục hình 3 tháng chức năng nhai đạt mức độ tốt là $100 \%$ (tăng lên) do có 2 bệnh nhân đã thích nghi với phục hình mới

- Sự hài lòng của bệnh nhân sau phục hình 3 tháng vẫn là $100 \%$.

\section{KẾT LUẬN}

- Ngay sau khi phục hình cho thấy, tỷ lệ thành công đẹp về hình thể, màu sắc, đường viền lợi là rất cao: hình thể với $96,88 \%$, màu sắc với $100 \%$, đường viên lợi với $97,92 \%$.

- Sau lắp phục hình 3 tháng các tiêu chí đẹp về hình thể và màu sắc là không thay đổi, tiêu chí đường viền lợi thậm chí còn tăng lên

- Về chức nằng: $100 \%$ bệnh nhân có chức năng ăn nhai và phát âm không bị ảnh hưởng

- Độ bền: Không có trường hợp nào bị mẻ sứ, võ sườn, bong mặt dán trong thời gian theo dõi 3 tháng.

- Sau 3 tháng tình trạng vùng quanh răng và tình trạng răng trụ đều rất tốt, không có trường hợp nào có phục hình làm ảnh hưởng đến răng trụ và tổ chức quanh răng

- 100\% bệnh nhân đều hài lòng với kết quả phục hình.

\section{TÀI LIẸU THAM KHẢO}

1. Sheets CG,Taniguchi T.Advantages and lamitations in the use of porcelain veneer restorations. J prosthet Dent.1990;64(4):406411.doi:10.1016/0022-3913(90)9035-6

2. Strassler HE.Minimally invasive porcelain veneers:indications for a conservative esthetic dentistry treatment modality. Gen Dent.2007; 55(7): 686-712

3. Fradeani M,Redemagni M.,Corrado M.Porcelain laminate veneers:6-to 12-year clinical evaluationA RetrospectiveStudy. International Journal of Periodontics andRestorative Dentistry. 2005; 25(1):9-17

4. Chu Thị Quỳnh Hương (2010).Nghiên cứu và đánh giá kết quả sử dụng vất liệu toàn sứ IPS Empress 2 trong phục hình nhóm răng trước, Luận văn tiến sĩ y học, Trường Đại Học Y Hà Nội

5. Nobrega A.S., Silva Signoreli A.F. Quinelli Mazzaro J.V., Zavanelli R.A., Zavanell A.C.Minimally invasive preparationss:contact lenses.Journal of Advanced Clinical\&Research Insights. 2015;2:176-179.

6. Brodbelt RHW, O'Brien WJ, Fan PL (1980). "Translucency of dental porcelain". J Dent Res. Pp.59:70

7. Willard A, Gabriel Chu TM. The science and application of IPS .Max dental ceramic. Kaohsiung] Med Sci. 2018;34(4):238-242. doi: 10.1016/ j.kjms.2018.01.012

8. Peumans $M$, Van Meerbeek $B$, Lambrechts $P$, Vuylsteke- Wauters M, Vanherle G . Five-year clinical perfomance of porcelain veneers. Quintessence int . 1998;29(4):211-221

\section{ĐĂC ĐIỂM LÂM SÀNG VÀ CÂN LÂM SÀNG CỦA BÊ̂NH NHẦN GLÔCÔM ÁC TÍNH ĐÎ̀UU TRỊ BẰNG PHẪU THUÂTT}

\section{TÓM TẮT.}

Mục tiêu: Mô tả đặc điểm lâm sàng và cận lâm sàng của bệnh nhân glốcôm ác tính phải điêu trị bằng phẫu thuật. Phương pháp nghiên cứu: mô tả cắt ngang. Kết quả: Nghiên cứu gồm 53 mắt glôcôm ác tính của 46 người bệnh, tuối trung bình 59,7 , nữ chiếm $76,1 \%$. 77,4\% mắt có chẩn đoán glôcôm góc đóng trước khởi phát glôcôm ác tính. Đa số phẫu thuật trước đó là cắt bè củng giác mạc (CGM) $(77,4 \%)$. Số mắt có trục nhãn câu $\leq 22 \mathrm{~mm}$ chiếm $71,7 \%$. TNC trung bình $21,7 \mathrm{~mm}$. Hình ảnh thể mi det và quay trước trên siêu âm UBM gặp ở $85 \%$ các

${ }^{1}$ Bệnh Viện Mắt Trung ương

Chịu trách nhiệm chính: Đố Tấn

Email: dotan20042005@yahoo.com

Ngày nhận bài: 3.3.2021

Ngày phản biện khoa học: 19.4.2021

Ngày duyệt bài: 3.5.2021

\section{Phạm Thị Thu Hà1, Đỗ Tấn ${ }^{1}$}

trường hợp. Kết luận: Glôcôm ác tính thường xuất hiện trên những người bệnh lớn tuổi, nữ giới, bị Glồcôm góc đóng, đã phẫu thuật cắt bè CGM trước đó và có trục nhãn cầu ngắn.

Tư khóa: Glôcôm ác tính, trục nhãn câu, thể mi xoay trước

\section{SUMMARY \\ CLINICAL AND IMAGING FEATURES OF MALIGNANT GLAUCOMA PATIENTS NEEDING SURGICAL TREATMENT}

Objectives: To describe the clinical and imaging features of malignant glaucoma patients who needed surgical interventions. Patients and Methods: descriptive cross sectional study. Results: study recruited 53 eyes from 46 patients who finally treated by surgical interventions. Mean age was 59,7 year old, female accounted for $76.1 \%$. $77.4 \%$ was diagnosed with PACG before the onset of malignant glaucoma. 